Rabaska

Revue d'ethnologie de l'Amérique française

\title{
Société internationale du réseau ÉCONOMUSÉE
}

\section{Lucie Marcoux}

Volume 3, 2005

URI : https://id.erudit.org/iderudit/201750ar

DOI : https://doi.org/10.7202/201750ar

Aller au sommaire du numéro

Éditeur(s)

Société québécoise d'ethnologie

ISSN

1703-7433 (imprimé)

1916-7350 (numérique)

Découvrir la revue

Citer ce document

Marcoux, L. (2005). Société internationale du réseau ÉCONOMUSÉE. Rabaska, 3 , 218-219. https://doi.org/10.7202/201750ar d'utilisation que vous pouvez consulter en ligne.

https://apropos.erudit.org/fr/usagers/politique-dutilisation/ 
Société internationale du réseau ÉCONOMUSÉE 203, Grande-Allée est Québec (Québec) G1R 2H8
Téléphone : (418) 694-4466

Télécopieur : (418) 694-4410 Courriel : info@economusees.com Toile : www.economusees.com

Un bel arrivage de nouveaux membres à visiter dans le réseau des Économusées

Le Réseau des Économusées ne cesse de s'agrandir, visant à couvrir peu à peu tous les métiers traditionnels et toutes les régions du Québec.

Ainsi, le 11 novembre 2004, le Forgeron d'or, économusée de la bijouterie, ouvrait ses portes pour la première fois à ses clients en tant qu'économusée. Situé à Sainte-Marie en Beauce, le Forgeron d'or est le premier économusée à voir le jour dans cette région. Richard Grenier et Agnès Goujon, propriétaires de l'entreprise, se spécialisent dans la fabrication, la transformation, la restauration et la réparation de bijoux, parures diverses et autres joyaux. Les bijoux, en or, en argent ou en platine sont agrémentés ou non de pierres fines et précieuses. Une des particularités du Forgeron d'or est la minisculpture de métaux précieux. Richard Grenier utilise tant la technique de la cire perdue que celle de la forge pour réaliser ses bijoux.

Un peu plus tard, le 9 décembre dernier, c'était au tour de la Verrerie d'art Touverre d'inaugurer son nouvel économusée en présence de plus de 150 invités. Giuseppe Benedetto pratique l'un des métiers les plus fascinants du monde, le soufflage du verre. L'atelier offre un éventail de pièces qui 
reflètent le traditionnel, le contemporain et l'expérimental. De l'assiette décorative au vase en passant par des fruits et des figurines animalières, ce qui caractérise le plus de travail de l'artisan, ce sont les teintes attrayantes de ses pièces, issues de différentes techniques de coloration. Touverre était également le premier économusée de sa région, le Saguenay-Lac-Saint-Jean.

L'économusée de la beurrerie, la Ferme Jean-Noël Groleau, de Compton, a pour sa part ouvert officiellement ses portes aux visiteurs le 10 mai dernier. Jean-Noël et Diane Groleau exploitent la seule entreprise à fabriquer du beurre artisanal au Québec. Leur beurre possède une saveur particulière parce qu'il est fabriqué à partir du lait du troupeau de la ferme et parce que les vaches de ce troupeau sont nourries et soignées sur place, différemment du cheptel voisin. Les beurres doux, demi-sel, salés et aromatisés sont produits sur place comme le lait, certains fromages et desserts laitiers offerts à la beurrerie. Son fromage cottage vient d'ailleurs de remporter le premier prix dans la catégorie des fromages non affinés au Festival du fromage de Warwick.

L'économusée de l'ébénisterie, l'Atelier Amboise, de Pohénégamook, a été inauguré le lundi 30 mai 2005. Le propriétaire, Martin Nadeau, se spécialise dans la reproduction de meubles traditionnels d'inspiration européenne et québécoise. Ses meubles sont toutefois faits sur mesure selon les besoins et ils se démarquent par leur qualité et la touche personnelle que l'artisan donne à chacun. Les armoires constituent la plus grande partie de la production, suivies des tables, buffets, commodes, armoires, vaisseliers, encoignures, tables et objets à dimensions plus restreintes. $M$. Nadeau va même jusqu'à adapter les outils existants ou à en créer de nouveaux pour mieux atteindre les résultats dignes de sa créativité.

L'économusée de la lainerie, le Chevrier du Nord, est la dernière entreprise à avoir lancé officiellement ses activités au grand public ce printemps, le 10 juin dernier. Propriété de la famille Pilote de Saint-Fulgence, au Saguenay, le Chevrier $d u$ Nord possède un troupeau d'une quarantaine de chèvres angoras dont elle transforme les toisons de mohair pour fabriquer des étoffes, tissus, tricots et feutres. Sous la griffe d'Annie Pilote, designer de mode, l'entreprise crée et vend des vêtements et accessoires fabriqués main, aux allures particulières et au style original. Le Chevrier du Nord est une jeune entreprise pleine de potentiel que la Société Économusée du Québec a acceptée dans le réseau parce qu'elle croit en son développement et en ses artisans.

LuCIE MarcouX 